\title{
Supplementary energy increases bone formation during arduous military training
}

Thomas J O’Leary ${ }^{1}$, Neil P Walsh ${ }^{2}$, Anna Casey ${ }^{1}$, Rachel M Izard ${ }^{3}$, Jonathan CY Tang ${ }^{4}$, William D Fraser ${ }^{4,5}$, Julie P Greeves ${ }^{1,4}$

\footnotetext{
${ }^{1}$ Army Health and Performance Research, Army Headquarters, Andover, United Kingdom; ${ }^{2}$ Research Institute for Sport and Exercise Science, Liverpool John Moores University, Liverpool, United Kingdom; ${ }^{3}$ Department of Occupational Medicine, HQ Army Recruiting and Initial Training Command, Upavon, United Kingdom; ${ }^{4}$ Norwich Medical School, University of East Anglia, Norwich, United Kingdom; ${ }^{5}$ Norfolk and Norwich University Hospital, Norwich, United Kingdom
}

Corresponding author: Thomas J O’Leary, Army Health and Performance Research, Andover, Hampshire, SP11 8HT, United Kingdom. Email: thomas.oleary100@mod.gov.uk

Author contributions: JPG and NPW designed the study and collected the data; AC designed the nutritional intervention; NPW, JCYT and WDF performed the biochemical analysis; TJO analysed the data and produced the manuscript; all authors edited and approved the manuscript.

Running title: Energy status and bone metabolism. 


\section{Abstract}

Purpose: To investigate the effect of supplementary energy on bone formation and resorption during arduous military training in energy deficit. Methods: Thirty male soldiers completed an 8 -week military combat course (mean $\pm \mathrm{SD}$, age $25 \pm 3$ years, height $1.78 \pm 0.05 \mathrm{~m}$, body mass $80.9 \pm 7.7 \mathrm{~kg}$ ). Participants received either the habitual diet (control group, $n=15$ ) or an additional 5.1 MJ $\cdot \mathrm{d}^{-1}$ to eliminate the energy deficit (supplemented group, $n=15$ ). Circulating markers of bone formation and resorption, and reproductive, thyroid, and metabolic status, were measured at baseline, and week 6 and 8 of training. Results: Bone ALP decreased in controls $\left(-4.4 \pm 1.9 \mu \mathrm{g} \cdot \mathrm{L}^{-1}\right)$ and increased in the supplemented group $\left(16.0 \pm 6.6 \mu \mathrm{g} \cdot \mathrm{L}^{-1}\right)$, between baseline and week $8(\mathrm{P}<0.001)$. P1NP increased between baseline and week 6 for both groups $\left(5.6 \pm 8.1 \mu \mathrm{g} \cdot \mathrm{L}^{-1}, \mathrm{P}=0.005\right) . \beta \mathrm{CTX}$ decreased between baseline and week 8 for both groups $\left(-0.16 \pm 0.20 \mu \mathrm{g} \cdot \mathrm{L}^{-1}, \mathrm{P}<0.001\right)$. Prolactin increased from baseline to week 8 for the supplemented group $\left(148 \pm 151 \mathrm{IU} \cdot \mathrm{L}^{-1}, \mathrm{P}=0.041\right)$. The increase in adiponectin from baseline to week 8 was higher in controls $\left(4.3 \pm 1.8 \mathrm{mg} \cdot \mathrm{L}^{-1}, \mathrm{P}<0.001\right)$ than the supplemented group $\left(1.4 \pm 1.0 \mathrm{mg} \cdot \mathrm{L}^{-1}, \mathrm{P}<0.001\right)$. IGF binding protein-3 was lower at week 8 than baseline for controls $\left(-461 \pm 395 \mathrm{ng} \cdot \mathrm{mL}^{-1}, \mathrm{P}<0.001\right)$. Conclusion: The increase in bone ALP, a marker of bone formation, with supplementation supports a role of energy in osteoblastic activity; the implications for skeletal adaptation and stress fracture risk is unclear. The mechanism is likely through protecting markers of metabolic, but not reproductive or thyroid, function.

\section{Key Words}

Bone Modelling; Energy Availability; Female Athlete Triad; Relative Energy Deficiency in Sport; Stress Fracture 


\section{Introduction}

Chronic low energy availability (energy intake minus exercise energy expenditure) increases bone resorption, decreases bone formation and areal bone mineral density, is detrimental to bone microarchitecture and mechanical strength, and increases stress fracture risk in female athletes (1-4). A decrease in bone formation is mediated by acute endocrine responses elicited by low energy availability — increased cortisol, and decreased 3,5,3-triiodothyronine (T3), leptin, and insulin-like growth factor 1 (IGF-1) $(1,2,4,5)$. Sustained, severe low energy availability downregulates the hypothalamic pituitary ovarian axis and suppresses oestradiol resulting in increased bone resorption $(1,2,5)$. The effect of low energy availability and arduous exercise on bone health is a widely recognised clinical phenomenon in female athletes (Female Athlete Triad) (2), but there is little evidence in men who make up most of the combat soldier population. There is some limited evidence men experience similar metabolic responses to low energy availability $(1,3)$.

Studies in male soldiers report endocrine changes during arduous military training characteristic of low energy availability: decreased IGF-1, testosterone, oestradiol, T3, and thyroxine (T4) occur after 5 days to 8 weeks of training (6-16). Energy availability is difficult to measure in free-living individuals, but energy deficits are estimated to be $\sim 4.2 \mathrm{MJ} \cdot \mathrm{d}^{-1}$ over the 8-week US Army Ranger course $(12,13)$, and $>29.3 \mathrm{MJ} \cdot \mathrm{d}^{-1}$ over shorter courses (5 days) (6-11). Military training is a multi-stressor environment involving strenuous exercise, restricted energy intake, sleep deprivation, and psychological stress. Endocrine disturbances are recovered with ad libitum re-feeding following training $(6-11,14)$ and are dependent on the severity of energy deficit $(17,18)$. Additional energy intake during military training attenuated disturbances to the thyroid hormones $(6,9,12)$ and IGF-1 axis (19), but not reproductive hormones $(10,12)$, however, the energy provision in these studies did not eliminate the energy 
deficit. Endocrine disturbances during military training are, therefore, likely mediated by energy deficiency and some of these disturbances may be prevented with energy supplementation.

Endocrine disturbances during arduous military training are associated with impaired bone health. Markers of bone formation and whole body mineral content (BMC) decreased in men with energy deficits of $\sim 4.2 \mathrm{MJ} \cdot \mathrm{d}^{-1}$ during 8 weeks of US Army Ranger training $(12,20)$. Furthermore, 61 days of energy deficit (13\% body mass loss) during an Antarctic crossing decreased bone formation and reduced areal bone mineral density at the axial skeleton of female British soldiers (21). Conversely, basic military training, which elicits only mild energy deficiencies, improved tibial bone density, bone macro- and microstructure, and estimated bone strength after 8 to 13 weeks (22-24). Increased markers of bone formation also supports an anabolic response to basic military training $(22,23,25)$.

Basic military training is osteogenic at weight-bearing sites (22-24), but advanced military training courses and field exercises conducted in energy deficit decrease bone formation and increase bone resorption, and result in bone loss from the axial skeleton. We have previously shown that an 8-week, arduous combat course for male soldiers resulted in an energy deficit of 2.7 $\mathrm{MJ} \cdot \mathrm{d}^{-1}(26)$. The primary aim of this study was to investigate the effect of providing supplementary energy on bone formation and resorption during the same 8-week, arduous military course. Secondary aims were to examine the reproductive, thyroid, and metabolic hormones important in the regulation of bone formation and resorption. We hypothesised that training would decrease bone formation and increase bone resorption, and that supplementary energy would protect against these disturbances. Modifying energy status during high levels of 
physical activity may also help to better understand the Athlete Triad and Relative Energy Deficiency in Sport syndromes in men.

\section{Materials and Methods}

\section{Participants}

Thirty healthy male British Army infantry soldiers participated in this unblinded, nonrandomised controlled trial. All participants were completing the 15-week British Army Section Commander's Battle Course at the Infantry Battle School, Brecon, UK. The participants were spread across two training platoons; one platoon formed the control group ( $n$ $=15)$ and started training in November, and one platoon formed the supplemented group $(n=$ 15) and started training in January. There was no difference between groups for age, height, body mass, lean mass, or body fat (Table 1). All participants provided written informed consent following a verbal and written brief of the study. Ethical approval was provided by the Ministry of Defence Research Ethics Committee (84/Gen/09).

\section{Study Design}

The Section Commanders' Battle Course is a 15-week training course for infantry soldiers, divided into two phases. The first phase is 7 weeks of classroom-based training, where candidates learn how to plan and conduct firing on fixed range complexes. The second phase is 8 weeks of physically demanding training on hilly and mountainous terrain to develop combat expertise in the field and is the focus of this study. Typical activities include small unit tactical operations, long patrols whilst carrying heavy loads, and repeated section attacks. The first 6 weeks of the second phase are spent in barracks with the training taking place in the local training area. The final 2 weeks are spent on a field exercise involving rigorous training and testing of the previous aspects of the course. Total energy expenditure and energy deficit 
were measured during the previous course (26). Total energy expenditure was 19.6 and 21.3 $\mathrm{MJ} \cdot \mathrm{d}^{-1}$ during weeks 2 to 3 and weeks 6 to 7 , total energy deficit was $2.7 \mathrm{MJ} \cdot \mathrm{d}^{-1}$, and body mass loss was $5.1 \mathrm{~kg}(6.0 \%)$. Upon completion of the course, candidates are promoted (from lance corporal to corporal) to infantry section commanders. Each participant had a blood sample taken at baseline (week 1), and week 6 and week 8 of the second phase of the course. A whole-body dual-energy x-ray absorptiometry (DXA) scan was performed at week 1 and week 8.

\section{Diet}

Food was provided from operational ration packs (for two meals or more) for 18 days when soldiers were on field exercises, and from cookhouse or container and packed meals for 37 days when soldiers were in barracks (including two days where breakfast or dinner only were supplied by operational ration packs). Soldiers are provided an energy intake of $14.0 \mathrm{MJ} \cdot \mathrm{d}^{-1}$ during weeks 0 to 6 and $17.7 \mathrm{MJ} \cdot \mathrm{d}^{-1}$ during weeks 6 to 8 , and typically self-supplement their diet by $2.9 \mathrm{MJ} \cdot \mathrm{d}^{-1}(19,26)$. The control group were fed the habitual diet and the supplemented group received an additional 5.1 $\mathrm{MJ} \cdot \mathrm{d}^{-1}\left(5.7 \mathrm{MJ} \cdot \mathrm{d}^{-1}\right.$ during weeks 0 to 6 , and $3.6 \mathrm{MJ} \cdot \mathrm{d}^{-1}$ during weeks 6 to 8). Since we did not want soldiers using the nutritional supplement as an alternative to food they might normally self-supplement, and allowing for a small increase in food provision since the previous course $\left(0.5 \mathrm{MJ} \cdot \mathrm{d}^{-1}\right)$, we provided a nutritional supplement to cover both the estimated energy deficit $\left(2.7 \mathrm{MJ} \cdot \mathrm{d}^{-1}\right)$ and self-supplementation $\left(2.9 \mathrm{MJ} \cdot \mathrm{d}^{-1}\right)$, thus providing 5.1 MJ $\cdot \mathrm{d}^{-1}$. Supplementary energy during field exercises was provided with: i) one shelf-stable ready-to-eat self-heating main meal with water sachet, plus flapjack bar (6 day supply), or; ii) one shelf-stable ready-to-eat main meal, plus flapjack bar (6 day supply), or; iii) one shelf-stable freeze-dried main meal, plus protein bar (6 day supply). The energy content of each supplement combination was the same and the military training staff provided the meal 
combination best suited to each stage of field training. Supplementary energy in barracks was provided with individual zip lock bags containing a range of shelf-stable ready-to-eat products to be eaten over $24 \mathrm{~h}$, including carbohydrate and protein-based recovery bars, nuts, raisins, flapjack, chocolate, and beef jerky. The supplement combinations consisted of $\sim 45 \%$ carbohydrate, $\sim 40 \%$ fat, and $\sim 15 \%$ protein, which matched the composition of the habitual control diet. The combination of supplements was based on previously established soldier preferences and consultation with platoon staff. Supplement adherence was assessed by daily collection of all food wrappers and packaging, and weighing uneaten foods.

\section{Markers of Bone Formation and Resorption, and Endocrine Function}

Blood samples were collected by venepuncture from an antecubital vein and taken between 05:30 and 06:00 $\mathrm{h}$ after an overnight fast and $12 \mathrm{~h}$ since the last exercise bout. Samples were centrifuged at $1500 \mathrm{~g}$ for $10 \mathrm{~min}$ in a refrigerated centrifuge, aspirated and aliquoted, and frozen at $-40{ }^{\circ} \mathrm{C}$. Samples were analysed in duplicate using commercial enzyme-linked immunosorbent (ELISA) assays for total IGF-1 (Immunodiagnostics Systems, UK), leptin (BioVendor, Czech Republic), and peptide YY (BioVendor, Czech Republic) in serum, and IGF binding protein-1 (IGF BP-1) (Medix Biochemica, Finland), IGF binding protein-3 (IGF BP-3) (R \& D Systems, USA), and testosterone (DRG Instruments GmbH, Germany) in plasma with inter-assay $\mathrm{CVs}$ across the measurement range of $\leq 8 \%$. Plasma procollagen type $1 \mathrm{~N}$ terminal propeptide (P1NP) and beta carboxy-terminal cross-linking telopeptide of type 1 collagen $(\beta C \mathrm{TX})$, and serum luteinising hormone (LH), follicle stimulating hormone (FSH), oestradiol, thyroid stimulating hormone (TSH), free T3, free T4, sex hormone-binding globulin (SHBG), and prolactin were measured using electrochemiluminescence immunoassay (ECLIA) on the COBAS e601 analyser (Roche Diagnostics, Mannheim, Germany) according to the manufacturer's instructions, with inter-assay CVs across the measurement range of $\leq$ 
4.0\%. Serum androstenedione was analysed by liquid chromatography tandem mass spectrometry (LC-MS/MS), the methods were calibrated using commercial standards (Chromsystems, Germany) traceable to standard reference material SRM971 from the National Institute of Science and Technology (NIST). Samples were extracted using ISOLUTE $^{\circledR}$ supported liquid extraction (SLE+) plates (Biotage, Sweden). The inter-assay CVs across the measurement range was $\leq 8 \%$. Serum bone-specific alkaline phosphatase (bone ALP) concentrations were determined by MicroVue ${ }^{\mathrm{TM}}$ ELISA kit (Quidel Corporation, US), with inter-assay $\mathrm{CV}$ across the measurement range of $\leq 8 \%$. Serum adiponectin was measured by $\mathrm{ALPCO}^{\circledR}$ total adiponectin ELISA kit (American Laboratory Products Company, US), with inter-assay $\mathrm{CV}$ across the measurement range of $\leq 6 \%$. Free testosterone was estimated using measured total testosterone and SHBG, and assuming an albumin concentration of $4.6 \mathrm{~g} \cdot \mathrm{dL}^{-1}$ (27). Complete data were unavailable for P1NP and $\beta \mathrm{CTX}$ (control, $n=1$; supplemented, $n=$ 4), bone ALP, peptide YY, adiponectin, and leptin (control, $n=1$ ), LH, FSH, and oestradiol (control, $n=2$; supplemented, $n=7$ ), androstenedione (control, $n=1$; supplemented, $n=8$ ), and prolactin (control, $n=2$; supplemented, $n=8$ ) due to insufficient sample.

\section{Bone Mineral Content}

Whole-body BMC was assessed by fan-beam DXA (QDR4500A, Hologic Systems, USA) with participants wearing shorts and a t-shirt. Upper and lower body BMC were derived from the whole-body scan. Lean and fat mass have been reported previously and were used to calculate energy deficit over the 8-week training period using the following equation $(19,28)$ :

Energy deficit $\left(\mathrm{MJ} \cdot \mathrm{d}^{-1}\right)=(\Delta$ fat mass $\times 38)+(\Delta$ lean mass $\times 6) / 56$ 
where $\Delta$ is the change in fat mass and lean mass, the energy densities of fat and lean mass are assumed to be 38 and $6 \mathrm{MJ} \cdot \mathrm{d}^{-1}$, and 56 represents the study duration in days.

\section{Statistical Analysis}

All data were analysed using SPSS (v.24, SPSS Inc., USA) and initially checked for normality. Baseline participant characteristics were compared between groups using an independent samples t-test for parametric data (height, body mass, lean mass, and body fat) and a MannWhitney $\mathrm{U}$ test for non-parametric data (age). Changes in markers of bone formation and resorption (P1NP, bone ALP, $\beta \mathrm{CTX}$ ), reproductive hormones (LH, FSH, oestradiol, total testosterone, free testosterone, SHBG, prolactin, androstenedione), thyroid hormones (T3, T4, TSH) and metabolic markers (IGF-1, IGF BP-1, IGF BP-3, leptin, peptide YY, adiponectin) were compared between groups using a $2 \times 3$ (group [control vs supplemented] $\times$ time [baseline vs week 6 vs week 8]) mixed-design ANOVA. Significant group $\times$ time interactions were explored with separate one-way repeated measures (main effect of time) ANOVAs for each group (Friedman test for non-parametric data), and independent samples t-tests were used to compare groups at each time-point (Mann-Whitney U Test for non-parametric data). Significant main effects of time were explored with post hoc uncorrected pairwise comparisons (Wilcoxon Signed Rank Test for non-parametric data) to identify differences between time points. Effect sizes are presented as Cohen's d (mean difference divided by pooled standard deviation) for between-group comparisons, Cohen's $d_{z}$ (mean difference divided by standard deviation of the mean difference) for within-group comparisons, and eta squared $\left(\eta^{2}\right)$ or partial eta squared $\left(\eta_{\mathrm{p}}{ }^{2}\right)$ for ANOVAs. Significance was accepted as $\mathrm{P}<0.05$.

\section{Results}

Supplement Adherence 
All participants in the control and supplemented group completed the study. The supplemented group consumed $66 \pm 13 \%$ of the $5.1 \mathrm{MJ} \cdot \mathrm{d}^{-1}$ supplement (week 1 to $6: 64 \pm 15 \%$ and week 7 to $8: 77 \pm 16 \%$ ). The main reported reason for non-compliance was lack of time to consume all the food. Based upon changes in fat mass and lean mass, it was estimated that the control group experienced a greater energy deficit than the supplemented group $\left(2.2 \pm 1.1\right.$ vs $0.7 \pm 1.1 \mathrm{MJ} \cdot \mathrm{d}^{-}$ $\left.{ }^{1}, \mathrm{P}<0.001\right)$, as reported previously $(19,28)$.

\section{Markers of Bone Formation and Resorption}

All markers of bone formation and resorption are presented in Figure 1. There was a significant main effect of time for P1NP and $\beta$ CTX $\left(\mathrm{P} \leq 0.011, \eta_{\mathrm{p}}{ }^{2} \geq 0.177\right)$, but no effect of supplementation (main effect of group, $\mathrm{P} \geq 0.269, \eta_{\mathrm{p}}{ }^{2} \leq 0.053$; group $\times$ time interaction, $\mathrm{P} \geq$ $\left.0.857, \eta_{\mathrm{p}}{ }^{2} \leq 0.007\right)$. P1NP was higher at week 6 than baseline $\left(P=0.005, d_{z}=0.73\right)$ and week $8\left(P=0.005, d_{z}=0.51\right) . \beta C T X$ was lower at week 8 than baseline $\left(P=0.001, d_{z}=-0.81\right)$ and week $6\left(\mathrm{P}<0.001, \mathrm{~d}_{\mathrm{z}}=-1.21\right)$. There was a significant group $\times$ time interaction for bone ALP $\left(\mathrm{P}<0.001, \eta_{\mathrm{p}}{ }^{2}=0.795\right)$. Separate one-way ANOVAs revealed a significant main effect of time for bone ALP for the control $\left(\mathrm{P}<0.001, \eta^{2}=0.740\right)$ and supplemented group $\left(\mathrm{P}<0.001, \eta^{2}=\right.$ 0.856). Bone ALP was lower at week 8 than baseline $\left(P<0.001, d_{z}=-2.38\right)$ and week $6(P<$ $\left.0.001, \mathrm{~d}_{\mathrm{z}}=-2.00\right)$ for the control group, but bone ALP was higher at week 8 than baseline (P $\left.<0.001, \mathrm{~d}_{\mathrm{z}}=2.43\right)$ and week $6\left(\mathrm{P}<0.001, \mathrm{~d}_{\mathrm{z}}=2.88\right)$ for the supplemented group. Bone ALP was higher for the supplemented group than the control group at week $8(\mathrm{P}<0.001, \mathrm{~d}=1.82)$.

\section{Reproductive Hormones}

All reproductive hormone data are presented in Figure 2. Testosterone has been reported previously (19) but is included here for completeness. There was a significant main effect of time for LH, FSH, oestradiol, total testosterone, free testosterone, androstenedione, and SHBG 
(all $\mathrm{P} \leq 0.035, \eta_{\mathrm{p}}{ }^{2} \geq 0.162$ ), but no effect of supplementation (main effect of group, all $\mathrm{P} \geq$ $0.2229, \eta_{\mathrm{p}}^{2} \leq 0.069$; group $\times$ time interaction, all $\left.\mathrm{P} \geq 0.273, \eta_{\mathrm{p}}{ }^{2} \leq 0.065\right)$. LH was higher at week 8 than baseline $\left(P=0.013, d_{z}=0.66\right)$. FSH was higher at week 8 than baseline $(P<0.001$, $\left.d_{z}=1.11\right)$ and week $6\left(P=0.040, d_{z}\right)$, and higher at week 6 than baseline $\left(P=0.031, d_{z}=0.80\right)$. Oestradiol, total testosterone, free testosterone, and androstenedione were lower $\left(d_{z} \leq-0.46\right)$, and SHBG was higher $\left(\mathrm{d}_{\mathrm{z}} \geq 0.97\right)$, at week 8 than baseline (all $\left.\mathrm{P} \leq 0.043\right)$ and week 6 (all $\mathrm{P}<$ 0.001). Androstenedione was also higher at week 6 than baseline $\left(P=0.030, d_{z}=0.47\right)$. There was a significant group $\times$ time interaction for prolactin $\left(P<0.001, \eta_{p}{ }^{2}=0.349\right)$. One-way ANOVAs revealed a significant main effect of time for prolactin for the control $\left(\mathrm{P}<0.001, \eta^{2}\right.$ $=0.522)$ and supplemented group $\left(P=0.024, \eta^{2}=0.463\right)$. Prolactin was higher at week 6 than baseline $\left(\mathrm{P}=0.002, \mathrm{~d}_{\mathrm{z}}=1.09\right)$ and week $8\left(\mathrm{P}=0.001, \mathrm{~d}_{\mathrm{z}}=1.19\right)$ for the control group, but higher at week 8 than baseline $\left(P=0.041, d_{z}=0.98\right)$ for the supplemented group. Prolactin was higher at week 8 for the supplemented than the control group $(P=0.003, d=1.09)$.

\section{Thyroid Hormones}

All thyroid hormone data are presented in Figure 3. There was a significant main effect of time for TSH and free T4 (both $\mathrm{P} \leq 0.001, \eta_{\mathrm{p}}^{2} \geq 0.231$ ), but no effect of supplementation (main effect of group, both $\mathrm{P} \geq 0.204, \eta_{\mathrm{p}}{ }^{2} \leq 0.057$; group $\times$ time interaction, both $\mathrm{P} \geq 0.295, \eta_{\mathrm{p}}{ }^{2} \leq 0.042$ ) TSH was lower at week 8 than baseline $\left(\mathrm{P}=0.016, \mathrm{~d}_{\mathrm{z}}=-0.46\right)$ and week $6\left(\mathrm{P}<0.001, \mathrm{~d}_{\mathrm{z}}\right.$ $=-1.63)$, and higher at week 6 than baseline $\left(P=0.003, d_{z}=0.60\right)$. Free T4 was higher at week 6 than baseline $\left(P=0.026, d_{z}=0.44\right)$ and week $8\left(P<0.001, d_{z}=0.86\right)$. There was no significant main effect of time $\left(P=0.207, \eta_{\mathrm{p}}^{2}=0.055\right)$ and no effect of supplementation for free $\mathrm{T} 3$ (main effect of group, $\mathrm{P}=0.069, \eta_{\mathrm{p}}{ }^{2}=0.113$; group $\times$ time interaction, $\mathrm{P}=0.145, \eta_{\mathrm{p}}{ }^{2}=0.067$ )

\section{Metabolic Hormones}


All metabolic hormone data are presented in Figure 4. Total IGF-1, IGF BP-1, and IGF BP-3 have been reported previously (19) but are included for completeness. There was a significant main effect of time for total IGF-1 and IGF BP-1 (both $\mathrm{P} \leq 0.009, \eta_{\mathrm{p}}{ }^{2} \geq 0.176$ ), but no effect of supplementation (main effect of group, both $\mathrm{P} \geq 0.307, \eta_{\mathrm{p}}{ }^{2} \leq 0.037$; group $\times$ time interaction, both $\left.P \geq 0.276, \eta_{\mathrm{p}}{ }^{2} \leq 0.044\right)$. Total IGF-1 was lower at week 8 than baseline $\left(P<0.001, d_{z}=\right.$ $-0.96)$ and week $6\left(P<0.001, d_{z}=-0.90\right)$, and higher at week 6 than baseline $\left(P=0.015, d_{z}=\right.$ 0.47). IGF BP-1 was lower at week 6 than baseline $\left(P=0.002, d_{z}=-0.64\right)$ and week $8(P=$ $\left.0.003, d_{z}=-0.62\right)$. There was a significant group $\times$ time interaction for IGF BP-3 $(P=0.017$, $\left.\eta_{\mathrm{p}}{ }^{2}=0.136\right)$. Separate one-way ANOVAs revealed a significant main effect of time for IGF BP-3 for the control group $\left(\mathrm{P}<0.001, \eta^{2}=0.622\right)$ but not the supplemented group $(\mathrm{P}=0.444$, $\left.\eta^{2}=0.056\right)$. IGF BP-3 was lower at week 8 than baseline $\left(P<0.001, \mathrm{~d}_{\mathrm{z}}=-1.17\right)$ and week 6 $\left(\mathrm{P}<0.001, \mathrm{~d}_{\mathrm{z}}=-1.58\right)$. IGF BP-3 was not different between groups at any time point $(\mathrm{P} \geq$ 0.174). There was no significant main effect of time $\left(P=0.164, \eta_{p}{ }^{2}=0.068\right)$ or effect of supplementation for peptide YY (main effect of group, $\mathrm{P}=0.262, \eta_{\mathrm{p}}{ }^{2}=0.046$; significant group $\times$ time interaction, $\left.\mathrm{P}=0.204, \eta_{\mathrm{p}}{ }^{2}=0.059\right)$. There was a significant group $\times$ time interaction for adiponectin $\left(\mathrm{P}<0.001, \eta_{\mathrm{p}}{ }^{2}=0.445\right)$. Separate one-way ANOVAs revealed a significant main effect of time for adiponectin for the control $\left(P<0.001, \eta^{2}=0.802\right)$ and supplemented group $\left(P<0.001, \eta^{2}=0.798\right)$. Adiponectin was higher at week 8 than baseline $\left(P<0.001, d_{z}=3.24\right)$ and week $6\left(P=0.024, d_{z}=0.68\right)$, and week 6 was higher than baseline $\left(P<0.001, d_{z}=1.86\right)$ for the control group. Adiponectin was higher at week 6 than baseline $\left(P<0.001, d_{z}=2.38\right)$ and week $8\left(P<0.001, d_{z}=1.50\right)$, with week 8 higher than baseline $\left(P<0.001, d_{z}=1.44\right)$ for the supplemented group. Adiponectin was higher in the control than the supplemented group at week $8(\mathrm{P}<0.001, \mathrm{~d}=1.54)$. There was a significant main effect of time for leptin $(\mathrm{P}=$ $0.006, \eta_{\mathrm{p}}^{2}=0.198$ ) but no effect of supplementation (main effect of group, $\mathrm{P}=0.950, \eta_{\mathrm{p}}{ }^{2}=$ 
0.000; group $\times$ time interaction, $\left.\mathrm{P}=0.543, \eta_{\mathrm{p}}{ }^{2}=0.019\right)$. Leptin was lower at week 8 then baseline $\left(P=0.005, d_{z}=-0.58\right)$ and week $6\left(P<0.001, d_{z}=-0.84\right)$.

\section{Bone Mineral Content}

All BMC data are presented in Figure 5. There was a significant main effect of time for upper body BMC $\left(\mathrm{P}=0.023, \eta_{\mathrm{p}}{ }^{2}=0.172\right)$, but no effect of supplementation (main effect of group, $\mathrm{P}$ $=0.535, \eta_{\mathrm{p}}{ }^{2}=0.014$; group $\times$ time interaction, $\left.\mathrm{P}=0.251, \eta_{\mathrm{p}}{ }^{2}=0.047\right)$. Upper body BMC was higher at week 8 then baseline. There was no significant main effect of time $\left(P=0.477, \eta_{\mathrm{p}}{ }^{2}=\right.$ 0.018) and no effect of supplementation for lower body BMC (main effect of group, $\mathrm{P}=0.526$, $\eta_{\mathrm{p}}^{2}=0.015 ;$ group $\times$ time interaction, $\left.\mathrm{P}=0.547, \eta_{\mathrm{p}}^{2}=0.013\right)$.

\section{Discussion}

This study reports the effect of supplementary energy on bone formation and resorption, and the endocrine regulators of bone, in male soldiers during an 8-week arduous military training course. Eight weeks of military training in energy deficit (control group) decreased bone formation and resorption, and disturbed markers of reproductive and metabolic function; $\beta C T X$, bone ALP, oestradiol, total testosterone, free testosterone, androstenedione, IGF-1, IGF BP-3, and leptin decreased, and LH, FSH, SHBG, and adiponectin increased. The smaller loss in lean and fat mass for the supplemented group compared with the control group, as previously reported, supports an attenuated energy deficit $\left(-0.7 \pm 1.1 \mathrm{MJ} \cdot \mathrm{d}^{-1} \mathrm{vs}-2.2 \pm 1.1 \mathrm{MJ} \cdot \mathrm{d}^{-1}\right)(19$, 28). In the supplemented group, bone ALP and prolactin increased, IGF BP-3 was maintained, and the increase in adiponectin was attenuated. Supplementary energy had no other effect on the bone or endocrine responses to military training. The supplementary food provided an increase in energy and macronutrients (in the same proportions as the control diet), did not include foods rich in vitamin D or calcium, and, therefore, did not change diet composition. 
The only difference between groups was the provision of supplementary energy; other multistressor characteristics of military training, such as strenuous exercise, sleep restriction, and psychological stress were unchanged and unlikely contributed to differences observed between groups.

\section{Markers of Bone Formation and Resorption}

We measured P1NP and bone ALP as markers of bone formation. Procollagen type $1 \mathrm{~N}$ terminal propeptide — a measure of type I collagen synthesis by the osteoblast (29) — was higher at week 6 compared with baseline, but not different between baseline and week 8 . The P1NP response to training was similar between groups. Bone-specific alkaline phosphatase a measure of osteoblast activity and mineralisation (29) - decreased in the control, but increased in the supplemented group, during 8 weeks of training. Procollagen type $1 \mathrm{~N}$-terminal propeptide and bone ALP reflect different bone formation processes, which may explain their different response to training and feeding. Laboratory studies show that short-term (5 days) low energy availability has no effect on P1NP production in men (30). We recently observed no change in P1NP in women following a 61 day Antarctic traverse, although the follow-up measurement was made 4 days after the expedition (21). Similar to this study, P1NP was unchanged $(22,23)$ or increased $(25)$ in response to 8 to 16 weeks of basic military training in men and women. The influence of energy status on the bone ALP response to military training is also supported by other military studies. Decreased bone ALP is reported following energy deficit during a 61 day Antarctic traverse in women (21), and 8 weeks of US Army Ranger training in men (20), whereas bone ALP increased, or was unchanged, in response to 8 to 16 weeks of basic military training in energy balance $(23,25)$. These studies support our finding that the bone ALP, but not P1NP, response to military training in men is influenced by energy status. Physical activity levels were similar between our control and supplemented groups (19, 
28), and so the differences in bone ALP were not due to differences in training load. Military combat training involves sleep deprivation. Sleep deprivation reduces bone ALP (31), however, both groups completed identical training programmes, and had a similar sex steroid response, and so sleep loss is an unlikely mechanism contributing to the differences between groups. We are, however, unable to determine whether differences in absolute intakes of nutrients, rather than energy, contributed to the increased bone ALP in the supplemented group.

Bone resorption - measured by $\beta \mathrm{CTX}$ - decreased from baseline to week 8 in both groups. The reduction in $\beta \mathrm{CTX}$ demonstrates that training decreased type I collagen degradation independently of energy status. Laboratory studies show that short-term (5 days) low energy availability had no effect on $\beta$ CTX in men (30). Military studies demonstrate no effect of energy deficit on the $\beta$ CTX response to 8 weeks US Army Ranger training in men (20), or a 61 day Antarctic traverse in women (21). Similar to our study, reduced $\beta$ CTX has been reported in response to 13 weeks of infantry basic military training in men and women (22). The change in $\beta C T X$ (and P1NP) in our study likely represents the bone modelling and/or remodelling response to mechanical loading (22-24). An increase in BMC, albeit small, was shown for the upper (1.0\%), but not lower body, supporting an adaptive bone response to loading. Soldiers carry heavy loads with their upper-body during training that may not reflect habitual physical activity (unlike lower limb loading). Anticipated changes in lower limb bone in response to military training of this duration are unlikely picked up by DXA (2.8\% increase (22)), with the $\mathrm{CV}$ of DXA appendicular bone outcomes $\leq 1.2 \%$ (unpublished data from our laboratory). We were, however, unable to differentiate axial from appendicular, and cortical from trabecular, sites. Future studies should consider imaging with high-resolution peripheral quantitative computed tomography to examine the effect of energy status and exercise on bone compartments and microarchitecture. Nevertheless, these data suggest that the type I collagen 
metabolic response (P1NP and $\beta \mathrm{CTX}$ ) to military training is independent of energy status, whereas bone ALP, indicative of osteoblast activity and bone mineralisation, increases with supplementary energy. Markers of bone formation and resorption cannot distinguish between bone modelling or remodelling, but supplementary energy may promote the formation of new bone in response to mechanical loading via bone modelling. Supplementary energy during arduous exercise may, therefore, be a strategy for reducing stress fracture risk without compromising training; an increase in new bone formation with mechanical loading will increase bone fatigue resistance (32) and reduce stress fracture risk. The mechanism for the increase in bone ALP with supplementary energy could be due to protective effects of feeding on reproductive, thyroid, and metabolic function $(1,2,4,5)$.

\section{Reproductive Hormones}

Military training decreased oestradiol, total testosterone, free testosterone, and androstenedione, and increased SHBG. These changes in sex steroid hormones were accompanied by an increase in the gonadotropins LH and FSH, which is in contrast to other military studies with more severe energy deficits $(8,12,14,17,33)$. Low testosterone initiates a positive feedback loop to the hypothalamic pituitary gonadal axis, and gonadotropins increase to maintain normal testosterone concentrations. The sex steroids, oestradiol and testosterone, are important regulators of bone (34). Oestradiol suppresses osteoclast activity (34) and low concentrations of oestradiol with energy deficiency increase bone resorption in active women $(1,2,5)$. The effect of energy restriction on sex steroid concentrations and bone in men is less well understood $(1,3)$, but sex differences in these responses has important considerations for the military. We observed a reduction in bone resorption despite reduced oestradiol and testosterone, and increased SHBG, possibly indicating that men are more resistant to the effect of energy deficiency than women (30) or mechanical loading was protective. Sex steroid 
hormones, and bone formation and resorption markers do, however, each have an independent relationship with the severity of energy restriction (5).

Supplementary energy had no protective effect on the sex steroid hormone response to military training. Military training studies consistently demonstrate that energy deficits ( 5 days to 8 weeks of 4.2 to $\geq 29.3 \mathrm{MJ} \cdot \mathrm{d}^{-1}$ ) increase $\mathrm{SHBG}$, and reduce oestradiol, testosterone, androstenedione, and prolactin $(7,8,10-15,17,18,35)$, in agreement with our data. The few military training studies that have provided supplementary energy found no protective effect on sex steroid concentrations $(10,12,35)$, also consistent with our data. Supplementary energy was likely not protective of sex steroids in our study, and these previous studies, because the additional energy was insufficient to eliminate the energy deficit or mechanisms other than energy deficiency, such as sleep deprivation (11) or high levels of physical activity, were responsible for the reduction in sex steroid concentrations. Supplementary energy did, however, increase prolactin at week 8. Prolactin increases bone formation directly through receptors on osteoblasts or indirectly through interactions with other reproductive hormones (36), and could explain the increase in bone ALP with supplementation. These reproductive hormone data, nevertheless, demonstrate that the increase in bone formation with additional energy intake is not due to the protection of sex steroid hormone concentrations.

\section{Thyroid Hormones}

Military training had minimal effect on thyroid hormones in either group; thyroid stimulating hormone was lower at week 8 than baseline but free T3 and free T4 were not reduced. Short periods of military training in energy deficit ( $\leq 7$ days) reduce TSH, T3, and/or T4 $(6,9,11$, 18), which is prevented by increasing energy intake to attenuate the energy deficit (9). The 8week US Army Ranger course increased TSH $(12,14,15)$, decreased T3 and T4 $(12,14)$, or 
did not affect T3 (15); periodic re-feeding during the course recovered low T3 concentrations (12). The thyroid hormone, T3, stimulates osteoblast proliferation and differentiation, and bone mineralisation (37), and reductions in T3 contribute to reduced bone formation with energy deficit (2). The energy deficit in this study may not have been severe enough to reduce T3, and similar thyroid responses between groups demonstrate that impaired thyroid function cannot explain differences in bone formation between groups.

\section{Metabolic Hormones}

Military training altered the IGF axis; total IGF-1 and IGF-BP 3 were lower at week 8 compared with baseline and week 6 , and IGF-BP 1 was higher at week 8 compared with week 6 in the control group. The 8-week US Army Ranger course reduced total IGF-1, increased IGF-BP 1 and, in contrast to our data, increased IGF-BP 3 (12-15). A reduction in total IGF-1 and IGF-BP 3 is shown in other studies examining several days of military training in energy deficit $(16,38)$. Supplementary energy had no effect on the total IGF-1 or IGF BP-1 response to training, but did maintain IGF BP-3 in our study. In contrast, total IGF-1 increased with periods of re-feeding during US Army Ranger training (12). Insulin-like growth factor 1 is an important regulator of bone formation $(39,40)$, and decreases in total IGF-1 with energy restriction contribute to decreases in bone formation $(1,2,5)$. The actions of the IGF binding proteins on bone are complex; IGF binding proteins regulate the bioavailability and local actions of IGF-1, but also act directly $(39,40)$. Insulin-like growth factor binding protein 1 is primarily inhibitory by preventing the binding of IGF-1 to the receptor, and IGF-BP 3 increases the bioavailability of circulating IGF-1 by making a tertiary complex, and directly stimulates osteoblasts (39). Maintaining IGF BP-3 with supplementary feeding may have contributed to the increase in bone ALP. Military training also decreased leptin and increased adiponectin, characteristic of energy deficiency (3). Leptin directly stimulates osteoblasts and can act 
indirectly on bone though effects on oestradiol, cortisol, IGF-1, and parathyroid hormone (41), whereas adiponectin can inhibit osteoblast activity (40). Supplementary energy had no effect on the leptin response to training but attenuated the increase in adiponectin, which may have decreased inhibition of osteoblast activity and contributed to the increase in bone ALP. These conclusions are speculative, but the data provide some evidence for the mechanism by which supplementary energy supports the adaptive bone formation response to military training.

\section{Limitations}

This study was a non-randomised trial; the control group completed training first (starting in November) and the supplemented group completed training in the subsequent course (starting in January). We opted against a randomised design trial to reduce the risk of those allocated to the control condition from supplementing their diet. The reported differences in bone formation and endocrine function between groups could, therefore, be due to differences between courses and time of year. Both courses followed identical training programmes, as shown by similar physical activity levels, and completed training in winter, and, therefore, we are confident differences between groups are due to energy status. The direct measurement of energy intake or expenditure was not possible, but the changes in body composition confirm supplementary energy was effective in attenuating the energy deficit compared with the control group. It is also possible that our bone ALP assay had some cross-reactivity with the liver ALP isoform, but the level of reactivity is low $(<8 \%)$ and unlikely explains our findings. Finally, the conclusions in this study are limited by the small sample size.

\section{Conclusion}

Supplementary energy, equal to two thirds of the calculated energy deficit, increased bone ALP (a marker of bone formation) in response to 8-weeks military training. The mechanism for this 
increase in bone ALP is unclear but could be due to an indirect effect of feeding on osteoblast function via increased prolactin, maintenance of IGF BP-3 and attenuation of adiponectin. The implications of the increased bone ALP for skeletal adaptations and stress fracture risk warrants further investigation.

\section{Acknowledgements}

The authors would like to thank the participants and staff at the Infantry School, Brecon, UK, without whom this study would not have been possible. The study was funded by the UK Ministry of Defence (Army).

\section{Competing Interests}

All authors are employees of, or were funded by, the UK Ministry of Defence (Army). The results of the present study do not constitute endorsement by ACSM. The results of this study are presented clearly, honestly, and without fabrication, falsification, or inappropriate data manipulation.

\section{References}

1. Mountjoy M, Sundgot-Borgen J, Burke L et al. The IOC consensus statement: beyond the Female Athlete Triad--Relative Energy Deficiency in Sport (RED-S). Br J Sports Med. 2014;48(7):491-7.

2. Nattiv A, Loucks AB, Manore MM et al. American College of Sports Medicine position stand. The female athlete triad. Med Sci Sports Exerc. 2007;39(10):1867-82.

3. Mountjoy M, Sundgot-Borgen J, Burke L et al. International Olympic Committee (IOC) Consensus Statement on Relative Energy Deficiency in Sport (RED-S): 2018 Update. Int J Sport Nutr Exerc Metab. 2018;28(4):316-31. 
4. Papageorgiou M, Dolan E, Elliott-Sale KJ, Sale C. Reduced energy availability: implications for bone health in physically active populations. Eur $J$ Nutr. 2018;57(3):847-59.

5. Ihle R, Loucks AB. Dose-response relationships between energy availability and bone turnover in young exercising women. J Bone Miner Res. 2004;19(8):1231-40.

6. Opstad PK, Falch D, Oktedalen O, Fonnum F, Wergeland R. The thyroid function in young men during prolonged exercise and the effect of energy and sleep deprivation. Clin Endocrinol. 1984;20(6):657-69.

7. Aakvaag A, Bentdal Ø, Quigstad K, Walstad P, Rønningen H, Fonnum F. Testosterone and Testosterone Binding Globulin (TeBG) in Young Men during Prolonged Stress. Int J Androl. 1978;1:22-31.

8. Aakvaag A, Sand T, Opstad PK, Fonnum F. Hormonal changes in serum in young men during prolonged physical strain. Eur J Appl Physiol. 1978;39(4):283-91.

9. Opstad PK, Aakvaag A. The effect of a high calory diet on hormonal changes in young men during prolonged physical strain and sleep deprivation. Eur J Appl Physiol. 1981;46(1):31-9.

10. Opstad PK, Aakvaag A. Decreased serum levels of oestradiol, testosterone and prolactin during prolonged physical strain and sleep deprivation, and the influence of a high calorie diet. Eur J Appl Physioly. 1982;49(3):343-8.

11. Opstad PK, Aakvaag A. The effect of sleep deprivation on the plasma levels of hormones during prolonged physical strain and calorie deficiency. Eur J Appl Physiol. 1983;51(1):97-107.

12. Friedl KE, Moore RJ, Hoyt RW, Marchitelli LJ, Martinez-Lopez LE, Askew EW. Endocrine markers of semistarvation in healthy lean men in a multistressor environment. J Appl Physiol (1985). 2000;88(5):1820-30. 
13. Nindl BC, Barnes BR, Alemany JA, Frykman PN, Shippee RL, Friedl KE. Physiological consequences of U.S. Army Ranger training. Med Sci Sports Exerc. 2007;39(8):1380-7.

14. Nindl BC, Friedl KE, Frykman PN, Marchitelli LJ, Shippee RL, Patton JF. Physical performance and metabolic recovery among lean, healthy men following a prolonged energy deficit. Int J Sports Med. 1997;18(5):317-24.

15. Henning PC, Scofield DE, Spiering BA et al. Recovery of endocrine and inflammatory mediators following an extended energy deficit. $J$ Clin Endocrinol Metab. 2014;99(3):956-64.

16. Nindl BC, Castellani JW, Young AJ et al. Differential responses of IGF-I molecular complexes to military operational field training. $J$ Appl Physiol (1985). 2003;95(3):1083-9.

17. Kyrolainen H, Karinkanta J, Santtila M, Koski H, Mantysaari M, Pullinen T. Hormonal responses during a prolonged military field exercise with variable exercise intensity. Eur J Appl Physiol. 2008;102(5):539-46.

18. Hamarsland H, Paulsen G, Solberg PA, Slaathaug OG, Raastad T. Depressed Physical Performance Outlasts Hormonal Disturbances after Military Training. Med Sci Sports Exerc. 2018;50(10):2076-84.

19. Fortes MB, Diment BC, Greeves JP, Casey A, Izard R, Walsh NP. Effects of a daily mixed nutritional supplement on physical performance, body composition, and circulating anabolic hormones during 8 weeks of arduous military training. Appl Physiol Nutr Metab. 2011;36(6):967-75.

20. Hughes JM, Smith MA, Henning PC et al. Bone formation is suppressed with multistressor military training. Eur J Appl Physiol. 2014;114(11):2251-9. 
21. O'Leary TJ, Gifford RM, Double RL et al. Skeletal responses to an all-female unassisted Antarctic traverse. Bone. 2019;121:267-76.

22. O'Leary TJ, Izard RM, Walsh NP, Tang JCY, Fraser WD, Greeves JP. Skeletal macroand microstructure adaptations in men undergoing arduous military training. Bone. 2019;125:54-60.

23. Hughes JM, Gaffney-Stomberg E, Guerriere KI et al. Changes in tibial bone microarchitecture in female recruits in response to 8weeks of U.S. Army Basic Combat Training. Bone. 2018;113:9-16.

24. Izard RM, Fraser WD, Negus C, Sale C, Greeves JP. Increased density and periosteal expansion of the tibia in young adult men following short-term arduous training. Bone. 2016;88:13-9.

25. Evans RK, Antczak AJ, Lester M, Yanovich R, Israeli E, Moran DS. Effects of a 4month recruit training program on markers of bone metabolism. Med Sci Sports Exerc. 2008;40(11 Suppl):S660-70.

26. Richmond VL, Horner FE, Wilkinson DM, Rayson MP, Wright A, Izard R. Energy balance and physical demands during an 8-week arduous military training course. Mil Med. 2014;179(4):421-7.

27. Vermeulen A, Verdonck L, Kaufman JM. A critical evaluation of simple methods for the estimation of free testosterone in serum. $J$ Clin Endocrinol Metab. 1999;84(10):3666-72.

28. Diment BC, Fortes MB, Greeves JP et al. Effect of daily mixed nutritional supplementation on immune indices in soldiers undertaking an 8-week arduous training programme. European journal of applied physiology. 2012;112(4):1411-8.

29. Civitelli R, Armamento-Villareal R, Napoli N. Bone turnover markers: understanding their value in clinical trials and clinical practice. Osteoporos Int. 2009;20(6):843-51. 
30. Papageorgiou M, Elliott-Sale KJ, Parsons A et al. Effects of reduced energy availability on bone metabolism in women and men. Bone. 2017;105:191-9.

31. Staab JS, Smith TJ, Wilson M, Montain SJ, Gaffney-Stomberg E. Bone turnover is altered during $72 \mathrm{~h}$ of sleep restriction: a controlled laboratory study. Endocrine. 2019;65(1):192-9.

32. Warden SJ, Hurst JA, Sanders MS, Turner CH, Burr DB, Li J. Bone adaptation to a mechanical loading program significantly increases skeletal fatigue resistance. J Bone Miner Res. 2005;20(5):809-16.

33. Gifford RM, O'Leary T, Cobb R et al. Female Reproductive, Adrenal, and Metabolic Changes during an Antarctic Traverse. Med Sci Sports Exerc. 2019;51(3):556-67.

34. Compston JE. Sex steroids and bone. Physiological reviews. 2001;81(1):419-47.

35. Guezennec CY, Satabin P, Legrand H, Bigard AX. Physical performance and metabolic changes induced by combined prolonged exercise and different energy intakes in humans. Eur J Appl Physiol. 1994;68(6):525-30.

36. Nicks KM, Fowler TW, Gaddy D. Reproductive hormones and bone. Curr Osteoporos Rep. 2010;8(2):60-7.

37. Bassett JH, Williams GR. Role of Thyroid Hormones in Skeletal Development and Bone Maintenance. Endocr Rev. 2016;37(2):135-87.

38. Nindl BC, Alemany JA, Kellogg MD et al. Utility of circulating IGF-I as a biomarker for assessing body composition changes in men during periods of high physical activity superimposed upon energy and sleep restriction. $J$ Appl Physiol (1985). 2007;103(1):340-6.

39. Govoni KE, Baylink DJ, Mohan S. The multi-functional role of insulin-like growth factor binding proteins in bone. Pediatr Nephrol. 2005;20(3):261-8. 
40. Lombardi G, Sanchis-Gomar F, Perego S, Sansoni V, Banfi G. Implications of exerciseinduced adipo-myokines in bone metabolism. Endocrine. 2016;54(2):284-305.

41. Upadhyay J, Farr OM, Mantzoros CS. The role of leptin in regulating bone metabolism. Metabolism. 2015;64(1):105-13. 


\section{List of Figures}

2

3 Figure 1. Markers of bone formation and resorption. A, procollagen $1 \mathrm{~N}$-terminal propeptide

4 (P1NP); B, bone-specific alkaline phosphatase (bone ALP); C, beta C-telopeptide cross-links 5 of type 1 collagen ( $\beta$ CTX).

$6 \quad{ }^{\text {aP }}<0.05$ vs baseline for control; ${ }^{\mathrm{b}} \mathrm{P}<0.05$ vs baseline for supplemented; ${ }^{\mathrm{C}} \mathrm{P}<0.05$ vs week 6 for control; ${ }^{\mathrm{d}} \mathrm{P}<$ $7 \quad 0.05$ vs week 6 for supplemented; ${ }^{\mathrm{P}}<0.05$ vs control at same time-point.

8

9 Figure 2. Reproductive hormones. A, luteinising hormone (LH); B, follicle stimulating hormone (FSH); C, oestradiol; D, total testosterone; E, free testosterone; F, androstenedione;

G, prolactin; H, sex hormone binding globulin (SHBG). ${ }^{\text {aP }}<0.05$ vs baseline for control; ${ }^{b} \mathrm{P}<0.05$ vs baseline for supplemented; ${ }^{\mathrm{P}} \mathrm{P}<0.05$ vs week 6 for control; ${ }^{\mathrm{d}} \mathrm{P}<$ 0.05 vs week 6 for supplemented; ${ }^{\mathrm{e}}<0.05$ vs control at same time-point.

Figure 3. Thyroid hormones. A, thyroid stimulating hormone (TSH); B, free 3,5,3triiodothyronine (T3); C, free thyroxine (T4). ${ }^{\mathrm{a}} \mathrm{P}<0.05$ vs baseline for control; ${ }^{\mathrm{b}} \mathrm{P}<0.05$ vs baseline for supplemented; ${ }^{\mathrm{C}} \mathrm{P}<0.05$ vs week 6 for control; ${ }^{\mathrm{d}} \mathrm{P}<$ 0.05 vs week 6 for supplemented; ${ }^{\mathrm{e}} \mathrm{P}<0.05$ vs control at same time-point.

Figure 4. Metabolic markers for the control (left panels) and supplemented (right panels) groups. A, insulin-like growth factor 1 (IGF-1); B, insulin-like growth factor binding protein 1 (IGF BP-1); C, insulin-like growth factor binding protein 3 (IGF BP-3); D, peptide YY; E, adiponectin; F, leptin. ${ }^{a} \mathrm{P}<0.05$ vs baseline for control; ${ }^{b} \mathrm{P}<0.05$ vs baseline for supplemented; ${ }^{\mathrm{P}} \mathrm{P}<0.05$ vs week 6 for control; ${ }^{\mathrm{d}} \mathrm{P}<$ 0.05 vs week 6 for supplemented; ${ }^{\mathrm{e}}<<0.05$ vs control at same time-point.

Figure 5. Bone mineral content (BMC). A, upper body BMC; B, lower body BMC. 